of myself as being a geneticist or an MRC man or this and that, and it seems to me such a fascinating field. You can approach it from physical medicine with human and humane interest and find such an enormous lot to do. I can't think that the psychologists are as well placed, and certainly not the sociologists. A lot of them are totally misled by bogus ideas. The psychologists are better than the sociologists, who get their ideas from social knowledge which is knowledge about societies and groups, not about individuals. And I think they go completely adrift when they come up against individuals. They have these dogmas, that a child's best place is with his mother, for instance. Even when the child is running away at every possible opportunity they still send him back. As for the neurologists, I have no hope for them at all. I think the neurologists could only advance if they really became neuropsychiatrists. If you are interested in brain function you must pay attention, a great interest, to the top level functions of the brain, that is the speech, emotional reaction, communication with other people at the highest level.

\title{
Brief Impressions of Psychiatry in China
}

\section{Anne Cremona-Barbaro, Maudsley Hospital, London}

Sir Desmond Pond's talk on 'A Visit to the Far East', published in the Bulletin, November 1980, included an outline of psychiatric practice in China today. I too was in China last year and was fortunate enough to visit two of its largest psychiatric hospitals, and it seemed to me that there might be a place for my own brief and informal impressions. Of the two hospitals, one was in Peking (or Beijing as it is now officially referred to), and the other in Shanghai. In China, most psychiatric hospitals are separate from the general People's Hospitals, and tend to be located in the suburbs. They are divided into acute hospitals and sanatoriums for the more chronically ill patients.

Both the hospitals which I visited were acute hospitals. I was made very welcome by the Directors, both of whom spoke English and were clearly very familiar with 'Western' psychiatry, including the British Journal of Psychiatry! Both hospitals served a staggering catchment area of between 8 and 10 million people, for which they each had approximately 1000 acute beds, together with a back-up sanatorium with approximately another 1000 beds for the more chronically ill patients.

The doctors working in the hospital are divided into psychiatrists, whose training and duties seem reasonably similar to ours, and medical assistants (or assistant doctors) who attend medical school rather than medical college, and whose training comprises three years. There are also "barefoot doctors' whose training consists of a few months instruction, and who function chiefly in the community. I was told that at the present time between 30 and $40 \%$ of the Chinese psychiatrists are female. Multidisciplinary teams of psychiatrists, medical assistants, psychologists and nurses seem to be the rule. Stories which have filtered through about doctors having to take their turn with the wardchores (cleaning, making beds, etc) are apparently true, but happily this is no longer the case. At one time most formal training of doctors and psychiatrists stopped altogether, and many eminent specialists and professors were expelled from their universities and clinics and sent to work in the paddy-fields.
Most medical colleges were closed down altogether until 1970 , when they re-opened to provide drastically shortened three-year courses. Today it is different, and doctors are once more receiving a full medical education.

In both the hospitals I visited the staff and the patients seemed very satisfied with the service provided. Minor administrative differences were immediately obvious to the 'Western' eye, for example, sexual segregation on the wards, and uniforms for everyone, white tunics for the nurses and patients, and white coats for the doctors. Another striking difference was how busy everyone seemed, none of the apathy so common among psychiatric patients at home being apparent. Everyone was out of bed (I believe a very strict line is taken!), and busy at occupational therapy, except for a handful of very acutely ill patients. The weather in China in summer is warm, and in the hospital in Peking occupational therapy was taking place in a central courtyard, in the open air. The occupational therapy which was taking place was reminiscent of the work in a rehabilitation or assessment unit, that is to say that the emphasis seemed to be on packing or manufacture of marketable objects (such as boxes, dolls, and stringbags), rather than on free creativity or abstract discussion. However, the patients seemed to be enjoying themselves, and to gain confidence and self-respect from this exercise. I was told that most of the boxes were used in the hospital (for example as containers for ampoules), while other objects such as the bags are sold outside. The patients receive no payment for their work (the explanation given was that they were already receiving social security), and the money made from the sale of these articles is used to buy things for the hospital. Psychiatric hospitals (and most other hospitals), are financed by the local government or occasionally by a commune, and the patients either pay nothing at all for their treatment, or they pay a small amount towards the cost of their food, drugs and accommodation. The employer, whether Government, commune or factory, also makes a contribution towards this. 
One very striking and touching difference is the almost total absence of patients with dementia, as these patients are almost always looked after at home by their families. Drug addiction in China has apparently not existed for several years. Alcoholism is also rare: in the hospital in Shanghai, over the last twenty years, only 65 cases of alcoholism have been seen, $10 \%$ of whom were foreign seamen. Neurosyphilis has not been seen for almost twenty years, and Huntington's chorea does not exist.

In both hospitals I was told that about $70 \%$ of the patients were suffering from schizophrenia, the rest being a mixed bag of manic-depressive illness, epilepsy, personality disorders and neuroses, including phobias. Psychopathy as a disease concept does not seem to be accepted to any significant extent. I also formed the impression, perhaps wrongly, that patients with confusional states were admitted to psychiatric hospitals more often than we are used to in the United Kingdom.

Diagnosis is based on the International Classification of Diseases, and is made by the more usual 'Western' criteria, for example Schneiderian first-rank symptoms. The manifestations of various psychiatric illnesses also seemed very similar. I wondered whether catatonia might not be commoner, having been shown a case in Peking, but was told that this is not so. Manic-depressive illness is said to be less common than in the West, and acute mania is supposed to be relatively rare, but again I saw a classic case in Peking. Both the psychiatrists I spoke to felt that hypochondriasis and somatic symptoms, particularly headache, more commonly accompanied depression than in the West, and in fact many of the herbal remedies used are directed towards alleviating these symptoms. In Peking I was also told that diurnal variation, loss of weight and insomnia are perhaps less routine accompaniments of depression than we are used to, and that gain in weight, hypersomnia and 'smiling depression' are not uncommon. Suicide appears to be very rare. Assessment of IQ is usually carried out by psychologists, and the most commonly used test is the Wechsler.

Basic drug treatment was familiar enough, phenothiazines, depot injections of neuroleptics, antidepressants, lithium and minor tranquillizers being used in the relevant conditions in roughly the same dosage as we are used to. However, herbal medicines are often used in conjunction with these drugs. These herbal medicines, some of which are over 2000 years old, are frequently mixed specially for the individual patient, depending on the particular combination of symptoms experienced, and according to the eight key-links (the Taoist concept of yin and yang, interior and exterior, cold and heat, and hypofunction and hyperfunction). This practice of varying the medicine according to the symptoms, as well as the disease, is known as 'bien cheng lun chih'. Herbal medicines are reputed to act more slowly but to have fewer side-effects than modern antipsychotic medication. Most of them are derived from folk medicine.

Probably the most striking deviation from Western therapeutic methods is in the use of acupuncture. Acupuncture is the insertion of needles at certain defined points in the body, producing sensations of numbness, distension or heaviness. It is used chiefly for auditory hallucinations, anxiety, insomnia, enuresis, and tardive dyskinesia, in a variety of conditions, including schizophrenia, manic-depressive illness, various neuroses, and even in dementia. Each session lasts twenty to thirty minutes, and a course consists of one session a day for up to a month, often administered on an out-patient basis. Needling may be by the traditional or electrical method, and in a third method small quantities of drugs are injected. Moxibustion is the application of burnt herbs to the puncture-sites, and is often combined with acupuncture. Improvement is said to take place in well over $50 \%$ of patients, and a study carried out in Shanghai claims to show that electrical acupuncture is as effective as chlorpromazine in schizophrenia, although it is not clear which particular symptoms are improved. Again the origins of acupuncture are lost in antiquity, but it was certainly in use over 2000 years ago, when stone needles were used.

Psychotherapy in China would seem to be mainly group therapy, although some individual therapy and behaviour therapy are also given. Family therapy, marital therapy, and sex therapy are practically non-existent, although relatives, neighbours and friends may be invited to join the group. The groups are led by a doctor, psychologist or nurse, and are more educational than psychodynamic, with less stress on mutual participation. The group leader chooses various relevant topics, and gives short talks on them, based mainly on Marx's theory of dialectical materialism, while the patients take notes and ask questions. Little or no importance is given to Freud, Jung or any of the well-known Western psychoanalysts.

In summary, my impression of psychiatry in China was that it was alive and well, and not as different as one might expect. It is generally somewhat more structured and formal, and incorporates a few methods which are new to us. The history of psychiatry in China is of course very ancient, mentioned for the first time over 2000 years ago, in The Yellow Emperor's Manual of Internal Medicine. I was impressed by the determination of the Chinese people to make up for the lost years in psychiatry in the shortest time possible.

My thanks are due to Drs Tien Zu-en and Yen Hou-Tsin, and to my interpreter Mrs Xie. 